\section{Genetic parameters and path analysis for root yield of cassava under drought and early harvest}

\author{
Carlos Roberto Silva de Oliveira ${ }^{1^{*}}$, Jerônimo Constantino \\ Borel $^{1}$, Danilo Alves Pereira ${ }^{1}$, Bruna Parente de Carvalho ${ }^{1}$, \\ Ericles da Silva Medrado ${ }^{1}$, Francine Hiromi Ishikawa ${ }^{1}$ and Eder \\ Jorge de Oliveira ${ }^{2}$
}

\begin{abstract}
The objectives of this study were to estimate genetic parameters and identify traits that contribute to early yield in Manihot esculenta Crantz. Ten traits were evaluated in two experiments, one with 138 genotypes and the other with 133, using a completely randomized block design with four replications. All genotype effects were significant. The accuracy was high for the traits, except leaf retention (0.57), and reliability ranged from 0.33 to 0.75 . Root weight (RW) and number of roots (NR) showed the highest selection effectiveness $(C V)$, although the estimate was less than 1. Moreover, RW and NR obtained high genetic correlation (0.70). Path analysis showed that only number of roots had a significant direct effect on root weight (0.49), and no indirect effect was found. Therefore, accessions exhibited sufficient genetic variability, and indirect selection based on early evaluation of number of roots can be applied in cassava breeding for fresh root yield, increasing gain over time.
\end{abstract}

Keywords: Manihot esculenta, drought tolerance, genetic variability, genotypic correlation

\section{INTRODUCTION}

Cassava (Manihot esculenta Crantz) is one of the most important carbohydrate sources in tropical and subtropical regions. In Brazil, it is mainly grown for its starchy tubers and as a staple food, or for industrial purposes focused on starch production (Rao et al. 2017, Vieira et al. 2020). Since cassava has higher tolerance to drought than other crops, it is widely grown in semiarid regions with mean annual rainfall less than $700 \mathrm{~mm}$ and long periods of drought that can last up to six months (El-sharkawy 2007). However, few genotypes have shown sustainable tuber yield in this type of environment, due to genotypic variability, phenological response, degree of water stress, and duration of the drought (Okogbenin et al. 2013, Vitor et al. 2019).

The critical period for the most severe effects of water deficit in the crop is from the first to fifth month after planting, corresponding to storage root formation and rapid shoot growth (Daryanto et al. 2016). In general, drought conditions have been shown to reduce fresh root yield from 38 to $87 \%$ (Aina et al. 2007, Okogbenin et al. 2013, Oliveira et al. 2017). Upon recovery from water stress, cassava rapidly generates new leaves with high photosynthetic rates and biomass yield, resulting in root production similar to non-stressed plants, except when drought occurs during the first three months of growth (El-sharkawy 2007).
Crop Breeding and Applied Biotechnology 21(3): e36162137, 2021 Brazilian Society of Plant Breeding. Printed in Brazil http://dx.doi.org/10.1590/198470332021v21n3a46
E-mail: carlos robertoliveira89@gmating author: (iD) ORCID: 000-0002-9962-5603

Received: 13 December 2020 Accepted: 27 July 2021 Published: 30 September 2021

${ }^{1}$ Universidade Federal do Vale do São Francisco, Campus Ciências Agrárias, Rodovia BR-407, km 12, Lote 543, s/n, Projeto de Irrigação Nilo Coelho, 56.300-000, Petrolina, PE, Brazil

2 Empresa Brasileira de Pesquisa Agropecuária, Embrapa Mandioca e Fruticultura, Rua Embrapa, s/n, 44.380-000, Cruz das Almas, BA, Brazil 
In commercial plantations, cassava is clonally propagated from stem cuttings for homogeneity in the field, maintaining stability in yield and plant architecture traits. In many breeding programs, it is propagated by seed after artificial crosses are made to obtain genetic variability, as heterozygous crosses between cassava parent plants produce progenies that are genetically diverse (Ceballos et al. 2020). Tolerance to abiotic stresses such as drought and the main economic traits like fresh root yield in cassava are quantitative traits; therefore, they are highly affected by environmental conditions (Oliveira et al. 2014, Oliveira et al. 2017). There are few studies that have evaluated genetic variability in cassava through a large number of genotypes to select for drought tolerance considering the accuracy of traits under field conditions (Oliveira et al. 2017).

In general, cassava breeding programs have been identifying and selecting genotypes that are tolerant to water stress through destructive sampling of plants to assess the storage roots. Most studies have collected the fresh root yield data at the end of the crop cycle, which generally occurs between 12 and 18 months after planting (Mulualem and Ayenew 2012, Vitor et al. 2019). This requires that experiments be maintained for long periods under field conditions, resulting in a costly process for selection and validation of the cassava genotypes that are promising for tolerance. Consequently, it is important to develop early phenotyping strategies that help breeders identify genotypes that provide high root yield under drought conditions (Ceballos et al. 2016, Nduwumuremyi et al. 2018, Kengkanna et al. 2019, Wang et al. 2021).

In this context, an alternative for shortening the cassava selection cycle and reducing the maintenance costs of the experiments is indirect selection during early stages. Selecting genotypes using traits of high reliability evaluated in the plant growth cycle that are closely correlated to root yield potential under drought may confer efficiency in selection of tolerant genotypes (Duque and Setter 2019). However, exploiting the numerous vegetative and agronomic traits that contribute to yield through simple correlation analysis alone is difficult, considering that crop yield is a complex trait (Akinwale et al. 2010, Adjebeng-Danquah et al. 2016).

Therefore, unlike correlation analysis, path analysis provides detailed knowledge of the causes of correlation between traits and their importance, indicating which are directly related to the main trait and which are related through other traits, in a secondary way. This knowledge is important for indirect selection, as it allows focusing on traits that make a large direct contribution to root yield in cassava under drought and early harvest (Pereira et al. 2018, Silva et al. 2019, Diniz and Oliveira 2019).

Information regarding associations between cassava root yield and other traits obtained in the early stages of the growth cycle may be effective in selection for tolerance to water stress. Thus, the objectives of this study were to estimate the genetic parameters of the morpho-agronomic traits and identify agronomic traits that contribute to early yield in cassava.

\section{MATERIAL AND METHODS}

\section{Characterization of the experimental area}

The experiments were carried out in the agricultural production sector of the Federal University of the São Francisco Valley (lat 9o 16' 10.10” S, long 40 33' 43.05” W, alt $373 \mathrm{~m}$ asl) in Petrolina, PE, Brazil. The topography is flat and soil type is Ultisol with a cohesive eutrophic horizon. The local climate is hot semi-arid, BSh, in the updated Köppen-Geiger climate classification system (Peel et al. 2007).

Two experiments were carried out under field conditions, the first from April to November 2018 and the second from November to June 2019. In the first experiment, 138 genotypes were evaluated, from which 38 genotypes were selected according to their higher performance. In the second experiment, the previous 38 selected genotypes plus 95 new genotypes were evaluated; the latter were chosen by their previous performance under drought obtained in other experiments, which included cultivars and accessions (Alves et al. 2007, Oliveira et al. 2015, Oliveira et al. 2017). The accessions used in the experiments consisted of a set of genotypes from the Cassava Germplasm Bank of Embrapa Mandioca e Fruticultura.

Each experiment was evaluated in a completely randomized block design with four replications. The experimental plots were composed of seven plants spaced at $0.8 \mathrm{~m}$ between plants and $1 \mathrm{~m}$ between rows. The three middle plants 
were evaluated in each plot, whereas data for shoot and root weight were collected using all the plants in the plot. Stem cuttings of $16 \mathrm{~cm}$ were used for planting, and the cassava crop practices recommended by Silva and Regitano Neto (2019) were adopted. The plants were harvested six months after planting (MAP) in both experiments.

Climatic variations were monitored by means of a meteorological station set up close to the experimental area. The crop coefficient $\left(K_{c}\right)$ was obtained from Keller and Bliesner (1990), and the crop evapotranspiration (ET $T_{c}$ was estimated. During the experiments, all blocks were irrigated up to two months after planting, and water was supplied daily based on rainfall and evapotranspiration measurements from previous days. During the third and fourth months, the amount of irrigation was $50 \%$ and $75 \%$ of $E T_{c^{\prime}}$ respectively. After that period, irrigation of the blocks was suspended until harvest. A drip irrigation system was used, and a summary of the amount of irrigation, rainfall, and ETc during the experiments in shown in Figure 1.

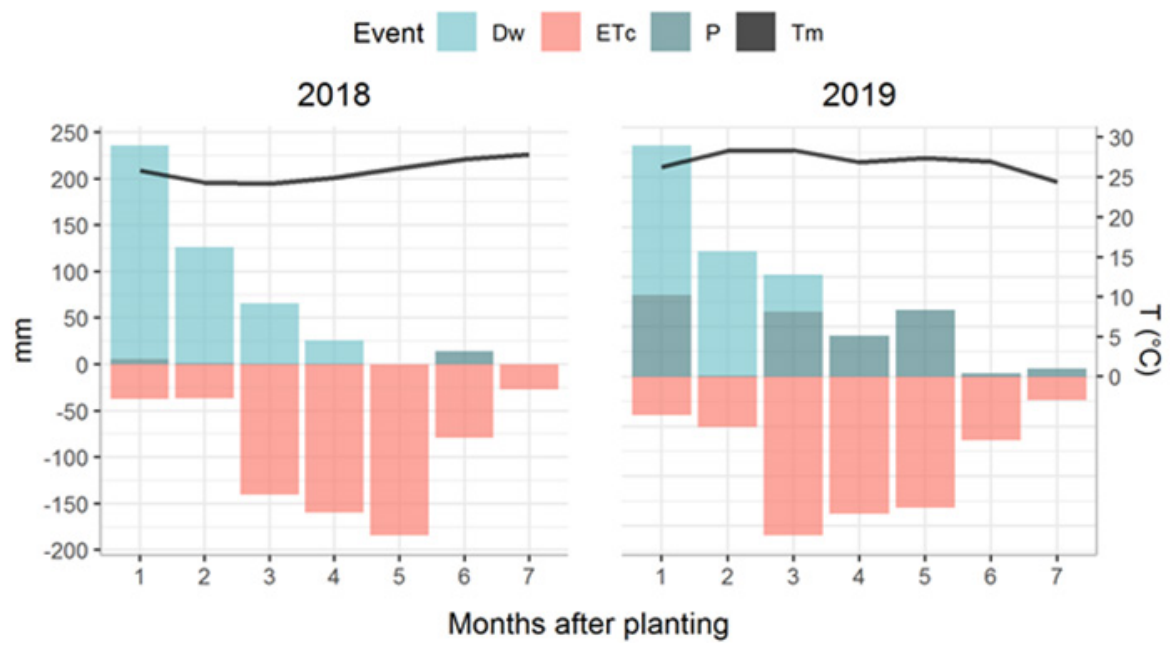

Figure 1. Monthly amount of drip irrigation (Dw), crop evapotranspiration (ETc), rainfall (P), and mean temperature (Tm) in each season.

\section{Traits measured}

At harvest time, the following traits were evaluated: plant height ( $\mathrm{PH}$, in $\mathrm{m})$, from the soil to the stem apex; number of above-ground stems (NS); stem diameter (SD, in cm) measured in the tallest stem using a digital caliper $20 \mathrm{~cm}$ above the soil; number of roots per plant (NR); root length ( $R L$, in $\mathrm{cm}$ ); root diameter (RD, in $\mathrm{cm}$ ) measured in the middle of the root using a digital caliper; total fresh root yield or weight (RW, in kg per plot); and shoot yield or weight (SW, in kg per plot).

Mite severity (CM), a visual rating of damage caused by mites, and leaf retention (LR), a visual rating of leaf longevity, were evaluated (Jiwuba et al. 2020).

\section{Genetic-statistical analyses}

The experimental data of the traits evaluated in the two seasons were analyzed to obtain the best linear unbiased predictor (BLUP) by the mixed model approach. The genetic parameters were estimated by the restricted maximum likelihood (REML) method using the "Ime4" package of the R version 3.4.4 software (R Development Core Team 2018), and significance for the variance components was determined through a likelihood ratio test (LRT) using the R package "LmerTest" (Kuznetsova et al. 2017). The BLUPs were extracted from the following model:

$$
Y_{i j k}=\mu+a_{k}+g_{i}+(r / a)_{j k}+e_{i j k}
$$

where $\mu=$ the effect of the general mean of the trait; $a_{k}=$ the fixed effect in year $k ; g_{i}=$ the random effect of genotype $i$; $r$ / $a)_{j k}=$ the random effect of repetition $j$ in year $k$; and $e_{i j k}=$ the random residual effect of genotype $i$ on repetition $j$ in year $k$. 
BLUPs were used to estimate the correlation coefficients between the characteristics; this analysis was carried out through the "corrplot" package of the R version 3.4.4 software (R Development Core Team 2018). The clone coefficient of variation $\left(C V_{c}\right)$, environmental coefficient of variation $\left(C V_{e}\right)$, and relative coefficient of variation $\left(C V_{r}\right)$ were estimated according to Resende and Duate (2007). Accuracy $\left(A_{c c}\right)$ and reliability $\left(i^{2}\right)$ were estimated according to the equations below (Bernardo 2020):

$$
\begin{gathered}
C V_{c}=\frac{\sigma_{c}}{\bar{Y}} \\
C V_{e}=\frac{\sigma_{e}}{\bar{Y}} \\
C V_{r}=\frac{C V_{c}}{C V_{e}} \\
A C c=\sqrt{1-\frac{P E V}{\sigma_{c}^{2}}} \\
i^{2}=\frac{\sigma_{c}^{2}}{\sigma_{f}^{2}}
\end{gathered}
$$

where $\sigma_{f}=$ phenotypic standard deviation; $\sigma_{e}=$ error standard deviation; $\sigma_{c}^{2}=$ clone variance; $\sigma_{f}^{2}=$ phenotypic variance; $\bar{Y}=$ experiment overall average; and $P E V=$ predicted error variance.

The path analysis was based on the genotypic correlation matrix of agronomic and yield traits of cassava genotypes considering root weight (RW) as the main variable, and the other nine traits were considered independent or explanatory variables. These analyses were performed using the Genes software (Cruz 2013).

\section{RESULTS AND DISCUSSION}

A faster method of developing new cassava varieties is through early evaluation and selection of genotypes using above-ground morphological traits (vegetative traits) as predictors of root yield (Andrade et al. 2019). The phenotypic mean values were in the range of $0.60-2.01 \mathrm{~m}$ for plant height, $1.00-4.58$ units for number of stems, score $1.00-5.00$ for leaf retention, score $2-4.58$ for mite severity, $1.25-3.17 \mathrm{~cm}$ for stem diameter, $0.33-1.33$ units for number of roots, $13.73-39.42 \mathrm{~cm}$ for root length, $1.21-4.90 \mathrm{~cm}$ for root diameter, $0.06-9.01 \mathrm{~kg} / \mathrm{plot}$ for root weight, and 0.15 $-15.33 \mathrm{~kg} /$ plot for shoot weight. The accuracy in the BLUP $\left(A_{c c}\right)$ estimates was considered moderate for leaf retention (0.54) (Table 1) and high for all other traits.

During the process of selecting accessions to increase drought tolerance, the traits to be considered as yield predictors must have high reliability, allowing the use of simple selection methods, which is especially important in clonally propagated crops such as cassava (Tuberosa 2012, Farshadfar et al. 2014). The shoot traits of plant height and number of stems had high reliability and significant clone variability; however, the contribution of these characteristics to root weight through genetic correlations were medium and low, respectively (Table 2). Therefore, these traits are less useful in direct selection for root yield.

Table 1. Genetic and phenotypic parameters estimated for plant height (PH), number of stems (NS), leaf retention (LR), mite severity $(C M)$, stem diameter $(S D)$, number of roots (NR), root length (RL), root diameter (RD), root weight (RW), and shoot weight (SW)

\begin{tabular}{lllllllllll}
\hline Parameters $^{\#}$ & PH & NS & LR & CM & SD & NR & RL & RD & RW & SW \\
\hline$\sigma_{c}^{2}$ & $0.021^{*}$ & $0.247^{*}$ & $0.075^{*}$ & $0.060^{*}$ & $0.037^{*}$ & $2.375^{*}$ & $6.452^{*}$ & $0.200^{*}$ & $1.768^{*}$ & $2.835^{*}$ \\
$\sigma_{e}^{2}$ & 0.057 & 0.435 & 0.667 & 0.202 & 0.107 & 3.465 & 29.264 & 0.423 & 2.492 & 7.838 \\
$\sigma_{f}^{2}$ & 0.078 & 0.682 & 0.742 & 0.262 & 0.144 & 5,840 & 35.716 & 0.623 & 4,260 & 10.673 \\
$i^{2}$ & 0.613 & 0.713 & 0.328 & 0.563 & 0.604 & 0.749 & 0.490 & 0.673 & 0.756 & 0.612 \\
$A_{c c}$ & 0.75 & 0.81 & 0.54 & 0.72 & 0.74 & 0.83 & 0.65 & 0.77 & 0.83 & 0.76 \\
$C V_{c}(\%)$ & 10.93 & 22.80 & 13.72 & 6.77 & 9.34 & 36.84 & 9.83 & 13.17 & 58.19 & 32.93 \\
$C V_{e}(\%)$ & 18.15 & 30.21 & 40.99 & 12.45 & 15.80 & 44.61 & 20.93 & 19.13 & 69.64 & 54.85 \\
$C V_{r}$ & 0.60 & 0.75 & 0.33 & 0.54 & 0.59 & 0.83 & 0.47 & 0.69 & 0.84 & 0.60 \\
$X_{f}$ & 1.32 & 2.18 & 1.99 & 3.61 & 2.06 & 4.17 & 25.84 & 3.40 & 2.28 & 5.10 \\
\hline
\end{tabular}

$\sigma_{c}^{2}$ : variance between clones; $\sigma_{e}^{2}$ : environmental variance; $\sigma_{f}^{2}:$ phenotypic variance; $i^{2}$ : reliability; $A_{c c}$ : accuracy; $C V_{c}$ : clone coefficient of variation; $C V_{e}$ : environmental coefficient of variation; $C V_{r}$ : relative coefficient of variation $\left(C V_{c} / C V_{e}\right)$, and $X_{f}$ : overall mean. *Significant in the likelihood ratio test (LRT) with $5 \%$ probability. 
Genetic parameters and path analysis for root yield of cassava under drought and early harvest

Table 2. Genotypic correlation coefficient (above diagonal), estimates of indirect effects (below diagonal), and direct effect on root weight (RW) through path analysis

\begin{tabular}{|c|c|c|c|c|c|c|c|c|c|}
\hline Traits & PH & NS & LR & $\mathrm{CM}$ & SD & NR & $\mathbf{R L}$ & RD & SW \\
\hline RW & $0.34^{*}$ & $0.24^{*}$ & $0.20 *$ & -0.08 & $0.18^{*}$ & $0.70 *$ & $0.53^{*}$ & $0.67^{*}$ & $0.52^{*}$ \\
\hline $\mathrm{PH}$ & - & 0.03 & $0.34^{*}$ & $-0.25^{*}$ & $0.47^{*}$ & $0.29 *$ & $0.42 *$ & $0.27^{*}$ & $0.47^{*}$ \\
\hline NS & -0.005 & - & 0.06 & 0.03 & $-0.17 *$ & $0.44^{*}$ & 0.06 & 0.10 & $0.36^{*}$ \\
\hline LR & -0.007 & -0.001 & - & $-0.47^{*}$ & $0.21^{*}$ & $0.15^{*}$ & $0.20 *$ & $0.35^{*}$ & 0.13 \\
\hline $\mathrm{CM}$ & -0.004 & 0.000 & -0.008 & - & -0.05 & -0.07 & -0.07 & $-0.15^{*}$ & -0.03 \\
\hline SD & -0.079 & 0.029 & -0.037 & 0.008 & - & $0.19 *$ & $0.43^{*}$ & $0.18^{*}$ & $0.36^{*}$ \\
\hline $\mathrm{RD}$ & 0.105 & 0.039 & 0.133 & -0.061 & 0.068 & 0.148 & 0.188 & - & $0.29 *$ \\
\hline SW & 0.140 & 0.109 & 0.038 & -0.010 & 0.108 & 0.112 & 0.111 & 0.086 & - \\
\hline Direct & -0.007 & -0.160 & -0.019 & 0.017 & -0.171 & 0.493 & 0.139 & 0.386 & 0.300 \\
\hline$R^{2}$ & 0.755 & & & & & & & ${ }^{*} \mathrm{RVE}$ & 0.495 \\
\hline
\end{tabular}

$R^{2}$ - coefficient of determination; ¥RVE - residual variance effect; RW - root weight; PH - plant height; NS - number of stems; LR - leaf retention; CM - mite severity; SD - stem diameter; NR - number of roots; RL - root length; RD - root diameter; and SW - shoot weight; * significant at 0.05 probability level.

The experimental error $\left(C V_{e}\right)$ was high for most of the traits of interest (Table 1), indicating that evaluations under water stress have relatively low experimental precision. Indeed, Silva et al. (2019) evaluated 49 accessions under drought conditions and found that the number of roots, shoot weight, and root weight also showed low clone variance in comparison with the residual variance. Even under drought during early stages in the growth cycle, the coefficient of clone variation $\left(C V_{c}\right)$ showed high estimates for number of roots $(36.84 \%)$, shoot weight (32.93\%), and root weight (58.19\%). These results confirm the high clone variability among the genotypes, which is necessary to develop cassava varieties with high root yield and drought stability. Similar results were reported by Oliveira et al. (2015) for these agronomic traits evaluated during harvest at 12 months after planting. Therefore, a striking feature of this information related to $C V_{c}$ for number of roots, shoot weight, and root weight is that these traits tend to remain stable over time, which makes it possible to select superior cassava clones during early evaluation for characteristics that effectively meet farmers' needs and expectations.

The relative coefficients of variation $\left(C V_{r}\right)$ were lower than 1 for all the traits analyzed, indicating an unfavorable situation for direct selection of these traits under drought and early harvest. When this occurs, due to higher environmental variation among genotypes than genetic variation, indirect selection carried out by means of path analysis in target environments can be a method that allows high genetic gains to be obtained (Diniz and Oliveira 2019).

Most of the genetic correlations between the morpho-agronomic traits were significant (Table 2), whose estimates showed different magnitudes, ranging from moderate correlation, between leaf retention $\times$ severity caused by mites $(-0.47)$, to high correlations, between weight $\times$ number of roots $(0.70)$ and weight $\times$ root diameter $(0.67)$. Therefore, both the number of roots and root diameter are good predictors of root yield in genotypes under drought and early harvest. Silva et al. (2019), studying different prediction models in drought environments, highlighted that the trait that most contributes to final root yield in well-watered and in water deficit treatments was the number of roots per plant. For Adu et al. (2018), in addition to traits related to shoot biomass, the root diameter (RD) trait has considerable potential for use as a predictor of tolerance to water stress and of nutrient use efficiency, and is useful in the selection of genotypes during initial growth stages. Therefore, the results obtained in this study indicate the possibility of obtaining genetic gains for root yield through use of the number and diameter of roots and its high correlation with root weight.

For mite severity (CM), the genetic correlations with shoot traits showed a tendency toward reduction in plant height and leaf retention in genotypes more susceptible to mite infestation. The traits associated with root quality, such as diameter, were also correlated with $\mathrm{CM}$, showing that even at the beginning of plant development, the pest potentially generates losses. However, there was no negative effect on root weight, which may be related to the ability of cassava to survive short-term biotic stress and recover high yield potential (Olasanmi et al. 2017). A cassava plant usually does 
not recover from a long period of severe mite attack, leading to a root yield reduction of up to $80 \%$ and low starch accumulation (Ezenkawa et al. 2018).

Direct selection for determination of root yield is a destructive evaluation. If vegetative traits at an early stage can be correlated to root weight, this will allow for development of effective genotype selection protocols. Even with a high residual correlation estimate, the path analysis based on the genetic correlation matrix, showed that a large part of the variation in root weight (RW) was explained by the effect of nine agronomic traits $\left(R^{2}>0.75\right)$. Thus, other factors or traits in addition to those studied are responsible for explaining root yield in cassava. Yield is a complex quantitative trait controlled by many genes, and so yield improvement largely depends on the functionality and interaction of several physiological components that vary for different genotypes (Rao et al. 2017). For that reason, Mulualem and Ayenew (2012) suggest not using final root weight (production) as an explanatory variable in the path analysis. Diniz and Oliveira (2019) report an alternative of using starch production as an explanatory trait. They obtained $R^{2}$ above $97 \%$ and a low residual correlation value $(0.14)$.

The direct effect of the number of roots on root weight in the path analysis was similar to the magnitude of the residual correlation effect, and therefore, the number of roots per cassava plant appears to have considerable potential for use in indirect selection. For all other traits, the values were below the residual correlation, indicating that they can be evaluated independently, because they did not show significant direct effects with root yield. In fact, Vitor et al. (2019) reported that the number of roots per plant did not change as plant development advanced, when two harvest periods (4 MAP and 12 MAP) were analyzed under drought and ideal water regime conditions. This indicates that in cassava the number of roots is defined early, and the nature of this trait is not greatly affected by environment, corroborating high estimates of reliability, relative coefficient of variation, and genotypic correlation and a direct effect on root weight. Furthermore, this same study showed a significant relationship between water treatments and harvest period for the traits of plant height, stem diameter, root length, and root diameter, all of which were lower when plants were subjected to drought and early harvest.

\section{CONCLUSION}

Phenotyping at six months after planting may be an effective way to promote early selection of drought-tolerant genotypes and, consequently, shorten the breeding cycle in cassava. Genotypes exhibited significant variability for all traits, and genotype prediction in cassava was satisfactory in terms of accuracy and reliability.

Indirect selection shows promise as a tool for identification of superior genotypes, since correlations for plant height, shoot weight, number of above-ground stems, stem diameter, leaf retention, number of roots, root diameter, and root length show genotypic correlation with yield under drought. The number of roots per plant showed the greatest magnitude for direct effects and high correlation with the main variable, root weight. Thus, number of roots per plant may be considered as a criterion in selection schemes for future genetic gains in root yield.

\section{REFERENCES}

Adjebeng-Danquah J, Gracen VE, Offei SK, Asante IK and ManuAduening J (2016) Agronomic performance and genotypic diversity for morphological traits among cassava genotypes in the Guinea Savannah Ecology of Ghana. Journal of Crop Science and Biotechnology 19: 99-108.

Adu MO, Asare PA, Asare-Bediako E, Amenorpe G, Ackah FK, Afutu E, Amoah MN and Yawson DO (2018) Characterising shoot and root system trait variability and contribution to genotypic variability in juvenile cassava (Manihot esculenta Crantz) plants. Heliyon 4: e00665.

Aina OO, Dixon AG and Akinrinde EA (2007) Effect of soil moisture stress on growth and yield of cassava in Nigeria. Pakistan Journal of Biological Sciences 10: 3085-3090.
Akinwale MG, Akinyele BO, Dixon AGO and Odiyi AC (2010) Genetic variability among forty-three cassava genotypes in three agroecological zones of Nigeria. Plant Breeding and Crop Science 2: 104-109.

Andrade LRBD, Sousa MBE, Oliveira EJ, Resende MDVD and Azevedo CF (2019) Cassava yield traits predicted by genomic selection methods. PloS One 14: e0224920.

Bernardo R (2020) Reinventing quantitative genetics for plant breeding: something old, something new, something borrowed, something BLUE. Heredity 125: 375-385.

Ceballos H, Pérez JC, Barandica OJ, Lenis JI, Morante N, Calle F, Pino L and Hershey CH (2016) Cassava breeding I: the value of breeding value. Frontiers in Plant Science 7: 1-12.

Ceballos H, Rojanaridpiched C, Phumichai C, Becerra LA, Kittipadakul 
P, Iglesias C and Gracen, VE (2020) Excellence in cassava breeding: Perspectives for the future. Crop Breeding, Genetics and Genomics 2: 1-31.

Cruz CD (2013) Genes: a software package for analysis in experimental statistics and quantitative genetics. Acta Scientiarum. Agronomy 35: 271-276.

Daryanto S, Wang L and Jacinthe PA (2016) Drought effects on root and tuber production: A meta-analysis. Agricultural Water Management 176: $122-131$.

Diniz RP and Oliveira EJ (2019) Genetic parameters, path analysis and indirect selection of agronomic traits of cassava germplasm. Anais da Academia Brasileira de Ciências 91: e20180387.

Duque LO and Setter TL (2019) Partitioning index and non-structural carbohydrate dynamics among contrasting cassava genotypes under early terminal water stress. Environmental and Experimental Botany 163: 24-35.

El-sharkawy MA (2007) Physiological characteristics of cassava tolerance to prolonged drought in the tropics: Implications for breeding cultivars adapted to seasonally dry and semiarid environments. Brazilian Journal of Plant Physiology 19: 257-286.

Ezenwaka L, Del Carpio DP, Jannink JL, Rabbi I, Danquah E, Asante I, Danquah A, Blay E and Egesi C (2018) Genome-Wide Association study of resistance to cassava green mite pest and related traits in cassava. Crop Science 58: 1907-1918.

Farshadfar E, Rahmani S, Jowkar MM and Shabani A (2014) Estimation of genetic parameters and chromosomal localization of QTLs controlling agro-physiological indicators of drought tolerance in agropyron using wheat-agropyron disomic addition lines. Australian Journal of Crop Science 8: 133-139.

Jiwuba L, Danquah A, Asante I, Blay E, Onyeka J, Danquah E and Egesi C (2020) Genotype by environment interaction on resistance to cassava green mite associated traits and effects on yield performance of cassava genotypes in Nigeria. Frontiers in Plant Science 11: 1-13.

Keller J and Bliesner RD (1990) Sprinkle and trickle irrigation. Van Nostrand Reinold, New York, 652p.

Kengkanna J, Jakaew P, Amawan S, Busener N, Bucksch A and Saengwilai P (2019) Phenotypic variation of cassava root traits and their responses to drought. Applications in Plant Sciences 7: e01238.

Kuznetsova A, Brockhoff PB and Christensen RHB (2017) LmerTest package: Tests in linear mixed effects models. Journal of Statistical Software 82: 1-26.

Mulualem T and Ayenew B (2012) Correlation and path coefficient analysis of cassava (Manihot esculenta Crantz) at Jimma, Southwestern, Ethiopia. Journal of Natural Sciences Research 2: 1-7.

Nduwumuremyi A, Melis R, Shanahan P and Theodore A (2018) Genetic inheritance of pulp colour and selected traits of cassava (Manihot esculenta Crantz) at early generation selection. Journal of the Science of Food and Agriculture 98: 3190-3197.
Okogbenin E, Setter TL, Ferguson M, Mutegi R, Ceballos H, Olasanmi B and Fregene $M$ (2013) Phenotypic approaches to drought in cassava. Frontiers in Physiology 4: 1-13.

Olasanmi B, Akoroda MO, Okogbenin E, Egesi C, Nwaogu AS, Tokula MH, Ukaa GT, Agba AJ, Ogbuekiri H, Nwakor W, Nwanguma F, EkeOkoro ON and Fregene M (2017) Identification of cassava (Manihot esculenta Crantz) genotypes with early storage root bulking. Journal of Crop Improvement 31: 173-182.

Oliveira EJ, Santana FA, Oliveira LA and Santos VS (2014) Genetic parameters and prediction of genotypic values for root quality traits in cassava using REML/BLUP. Genetics and Molecular Research 13: $6683-6700$.

Oliveira EJ, Morgante CV, Aidar ST, Chaves ARM, Antonio RP, Cruz JL and Coelho Filho MA (2017) Evaluation of cassava germplasm for drought tolerance under field conditions. Euphytica 213: 1-20.

Oliveira EJ, Aidar SDT, Morgante CV, Chaves ARDM, Cruz JL and Coelho Filho MA (2015) Genetic parameters for drought-tolerance in cassava. Pesquisa Agropecuária Brasileira 50: 233-241.

Peel MC, Finlayson BL and McMahon TA (2007) Updated world map of the Köppen-Geiger climate classification. Hydrology and Earth System Sciences 11: 1633-1644.

Pereira LFM, Zanetti S and Silva MA (2018) Water relations of cassava cultivated under water-deficit levels. Acta Physiologiae Plantarum 40: 1-13.

R Development Core Team (2018) R: a language and environment for statistical computing. R Foundation for Statistical Computing. Available at <http://www.R-project.org>. Accessed on 11 October, 2020.

Rao BB, Swami DV, Ashok P, Babu BK, Ramajayam D and Sasikala K (2017) Correlation and path coefficient analysis of cassava (Manihot esculenta (rantz) genotypes. International Journal of Current Microbiology and Applied Sciences 6: 549-557.

Resende MDV and Duarte JB (2007) Precisão e controle de qualidade em experimentos de avaliação de cultivares. Pesquisa Agropecuária Tropical 3: 182-194.

Silva AF and Regitano Neto A (2019) As principais culturas anuais na agricultura familiar. In Melo RF and Voltolini TV (eds) Agricultura familiar dependente de chuva no Semiárido. Embrapa, Brasília, p. 45-84.

Silva PPS, Sousa MB and Oliveira EJ (2019) Prediction models and selection of agronomic and physiological traits for tolerance to water deficit in cassava. Euphytica 215: 1-18.

Tuberosa R (2012) Phenotyping for drought tolerance of crops in the genomics era. Frontiers in Physiology 3: 1-26.

Vieira EA, Fialho JD, Oliveira CM, Rinaldi MM and Fernandes FD (2020) New cassava cultivars for starch and flour production in the Cerrado of Central Brazil. Crop Breeding and Applied Biotechnology 20: e27362023. 


\section{CRS Oliveira et al.}

Vitor AB, Diniz RP, Morgante CV, Antônio RP and Oliveira EJ (2019) Early prediction models for cassava root yield in different water regimes. Field Crops Research 239: 149-158.
Wang B, Guo X, Zhao P, Liao W, Zeng C, Li K, Zhou Y, Xiao J, Ruan M, Peng M, Bai Y and Chen Y (2021) MeMYB26, a drought-responsive transcription factor in cassava (Manihot esculenta Crantz). Crop Breeding and Applied Biotechnology 21: e34432114. 